Research Article

\title{
Seismic Performance Evaluation of Precast Concrete Beam-to-Shear Link Composite Connection with Bending Moment and Shear Force Separate Method
}

\author{
Shujun Hu, ${ }^{1,2,3}$ Qi Guo, ${ }^{2}$ Xinfu Xiong, ${ }^{1}$ and Jingang Xiong $\mathbb{D}^{2,3}$ \\ ${ }^{1}$ Zhongheng Construction Group Co. Ltd., Nanchang 330031, China \\ ${ }^{2}$ School of Civil Engineering and Architecture, Nanchang University, Nanchang 330031, China \\ ${ }^{3}$ Jiangxi Provincial Engineering Laboratory of Nearly Zero Energy Building, Nanchang 330031, China
}

Correspondence should be addressed to Jingang Xiong; xiongjingang@ncu.edu.cn

Received 20 January 2020; Revised 10 April 2020; Accepted 24 April 2020; Published 14 May 2020

Academic Editor: Elhem Ghorbel

Copyright $\odot 2020$ Shujun Hu et al. This is an open access article distributed under the Creative Commons Attribution License, which permits unrestricted use, distribution, and reproduction in any medium, provided the original work is properly cited.

A new type of prefabricated reinforced concrete-Y-shaped eccentrically steel brace structure (PRC-Y-ESBS) is developed by combining the mechanical property of prefabricated reinforced concrete frame and Y-shaped eccentrically steel brace, so the seismic performance and seismic resilience capacity of prefabricated reinforced concrete frame can be effectively improved. In the PRC-Y-ESBS, the precast concrete beam-to-shear link composite connection should have enough bearing capacity and resilience capacity under the shear force and bending moment, so the damage can be restricted in shear links. In this paper, an innovative precast concrete beam-to-shear link composite connection (PCB-SLCC) with bending moment and shear force separate method is proposed. Four different types of shear connectors are analyzed in detail by using the verified numerical method, and the shear capacity and failure mode of shear connectors can be obtained. Then, the innovative PCB-SLCCs with the reasonable shear connector considering different influencing parameters are also studied in detail. The results indicate that the shear connectors and high-strength bolts are still in elastic state at ultimate load, and little damage has occurred in the concrete between the embedded plate and precast concrete frame, while the PCB-SLCC has enough bearing capacity at the ultimate stage. In addition, this study also clearly identifies that high-strength bolts can only bear the bending moment, and the shear force is only carried by shear connectors, so the bending moment and shear force of the innovative PCB-SLCC with high bearing capacity, ease of installation, and seismic resilience capacity can be apparently separated.

\section{Introduction}

Based on the three-level earthquake resistant design [1] and the fifth-generation seismic ground motion parameter zonation map of China [2], a four-level seismic fortification objective of earthquake resilient structures and higher seismic performance was proposed [3]. Precast concrete frame structure (PCFS) is composed of precast concrete beams, precast concrete columns, and precast concrete dry connections, and all the components are assembled directly at location after processing in the factories [4]. However, the rotational stiffness, connection strength, and hysteretic behavior of precast concrete dry connection may perform poorly, so the ductility, lateral stiffness, and seismic performance of PCFS were obviously reduced [5]. The seismic performance and seismic resilience capacity of PCFS should be further improved so as to satisfy higher requirements.

Eccentrically braced frames (EBFs) had been accepted as a type of hybrid structural system with good lateral stiffness and ductility [6]. During a rare earthquake, the main structures (e.g., columns, beams outside of shear links, and braces) are always in the elastic stage, and the shear links in the EBFs are usually designed to allow high ductility and shear failure and dissipate seismic energy [7], which would be only repaired to restore the structural performance [8]. The shear link had a length ratio $\rho, l V_{p} / M_{p}$, less than 1.6, where $l, V_{p}$, and $M_{p}$ denote the length, plastic shear bearing 
capacity, and plastic flexural strength [1], respectively. The very short shear link was a special kind of shear link with length ratio lower than $1.0[9,10]$ and expressed a higher ductility, energy dissipation capacity, and elastic stiffness [11].

Previous studies have shown that the lateral stiffness, bearing capacity, and seismic performance of concrete frame structure can be effectively improved by combining the shear link and eccentrically steel brace [12]. Based on this, a new type of PRC-Y-ESBS is developed by introducing the very short shear links, $\mathrm{Y}$ shaped eccentrically steel braces, and pinned beam-to-beam connections into the prefabricated reinforced concrete frame, and the PRC-Y-ESBS will be effective in improving the seismic performance and seismic resilience capacity of prefabricated reinforced concrete frame [13], as shown in Figure 1.

During earthquakes, the ideal component damage of PRCY-ESBS should be restricted to the very short shear links, while the precast concrete column, precast concrete beam, steel brace, and all the connections are typically designed to be elastic. The precast concrete beam-to-shear link composite connection is the key component to transfer the shear force and bending moment, which is under complicated forces [14]. Extensive research has been focused on the connection performance of the concrete beam and shear link; it shows that the main components in the connection, such as shear connectors and concrete, may generate failure or plastic damage during the process of plastic deformation of shear links, making it difficult to repair after earthquakes [12,15-18]. Ghobarah and Abou Elfath [12] investigated the seismic performance of a reinforced concrete building rehabilitated using eccentric steel bracing. Mazzolani et al. [15] conducted experimental studies on the behavior of two-storey one-bay RC structures equipped with EBs and indicated that link end connections exhibited a key role in determining the system ductility, especially if bolted connections were selected for removable links. Durucan and Dicleli [16] studied the configuration of the link-brace system in application to RC frames by using 2-D and 3-D complex finite element analyses. Zhao et al. [17] indicated that the hysteresis curve of connection with $U$ shaped steel was full when the connected nodes between frame beams and shear link had higher bearing capacity, and the connection failure may cause the structure to collapse. Sun et al. [18] studied five full-scale connections between the RC frame beam and a shear link and indicated that the separation between the endplate of shear link and the top interface of the RC beam may lead to the pinching phenomenon of hysteretic curves and poor energy dissipation. In order to realize the seismic resilience, it is imperative to develop a new precast concrete beam-to-shear link connection, which can be easy to install and quickly repaired, so the earthquake damage to the PRC-Y-ESBS will be transferred from the main components to the very short shear links.

Based on seismic resilient capacity and damage control theory, an innovative precast concrete beam-to-shear link composite connection (PCB-SLCC) with bending moment and shear force separate method is firstly proposed. Then, the numerical models of three different shear connectors that are embedded between the very short shear link and precast concrete beam are analyzed by using the numerical method, which has been verified by comparison with the experimental data. Finally, the influencing parameters of concrete strength, shear connector length, end vertical plate height, and bolt spacing of PCB-SLCC with ideal shear connectors on the hysteresis curve, concrete damage, shear connector stress, and high-strength bolt stress are mainly studied. The ultimate goal is to investigate the seismic mechanism and failure modes, which laid the foundation for seismic resilience capacity.

\section{An Innovative Precast Concrete Beam-to-Shear Link Composite Connection (PCB-SLCC)}

2.1. Basic Composition of the Innovative PCB-SLCC. As shown in Figure 2, the PCB-SLCC is composed of five parts: the precast concrete beam, very short shear link, shear connectors, precast steel composite, and highstrength bolts. Endplate I and endplate II are welded at both ends of the very short shear link, while the stiffeners are all placed on both sides of the web of the very short shear link. The precast steel composite is composed of embedded plate I, embedded plate II, eight embedded sleeves, two shear plates, and four low modulus shims (e.g., rubber). Embedded plate I and embedded plate II are connected by welding the ends of eight embedded sleeves, and the three-edge weld is used to connect the two shear plates and embedded plate I on the other side of embedded sleeves, while the distance of two shear plates is same as the length of endplate I. In addition, the steel surface between embedded plate I and concrete will be smoothed, and the two shear connectors are, respectively, arranged on an extension of the two flanges of a very short shear link. The ends of embedded plate I and embedded plate II are bonded to four low modulus shims with a thickness of $2 \mathrm{~mm}$, and the diameter of high-strength bolt is $2 \mathrm{~mm}$ less than the diameter of the embedded sleeve, so the highstrength bolt can be an easy installation.

During the prefabrication, the very short shear link, shear connectors, and precast steel composite should be firstly processed. Then, the two shear connectors are welded with embedded plate I on the same side of the embedded sleeves, and the precast steel composite and shear connectors are arranged at the middle of the precast concrete beam. After that, the longitudinal and transverse reinforcements are embedded and then the concrete is poured into the beam. Finally, endplate I of shear link is set at the midway between the two shear plates, and eight high-strength bolts are used for quick assembly of PCB-SLCC in the construction site.

2.2. Working Principle of the Innovative PCB-SLCC. Shear connectors and high-strength bolts will play a key role in transferring the shear force and the bending moment between precast concrete beam and very short shear link, when subjected to rare earthquake events. The shear force transferred from the very short shear link to PCB-SLCC is delivered to the shear plates and finally carried by the shear 


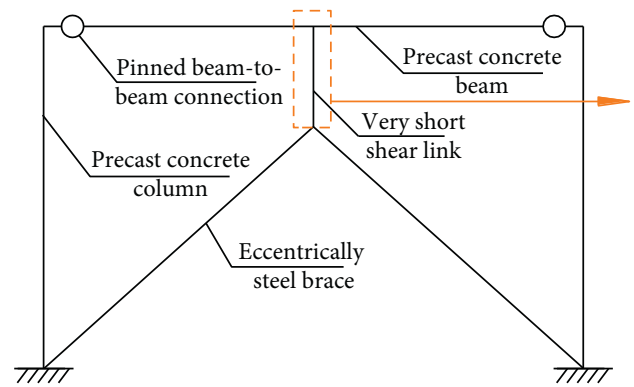

(a)

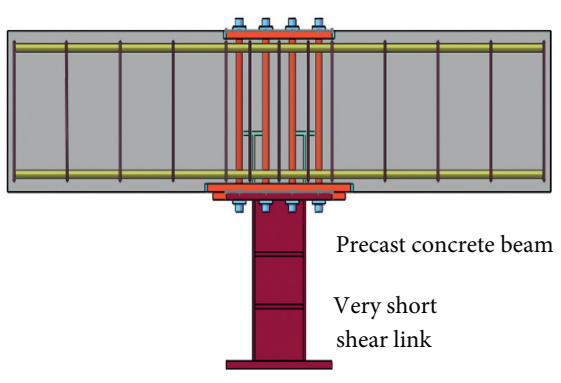

(b)

FIgURE 1: Prefabricated reinforced concrete-Y shaped eccentrically steel brace structure: (a) PRC-Y-ESBS; (b) PCB-SLCC.

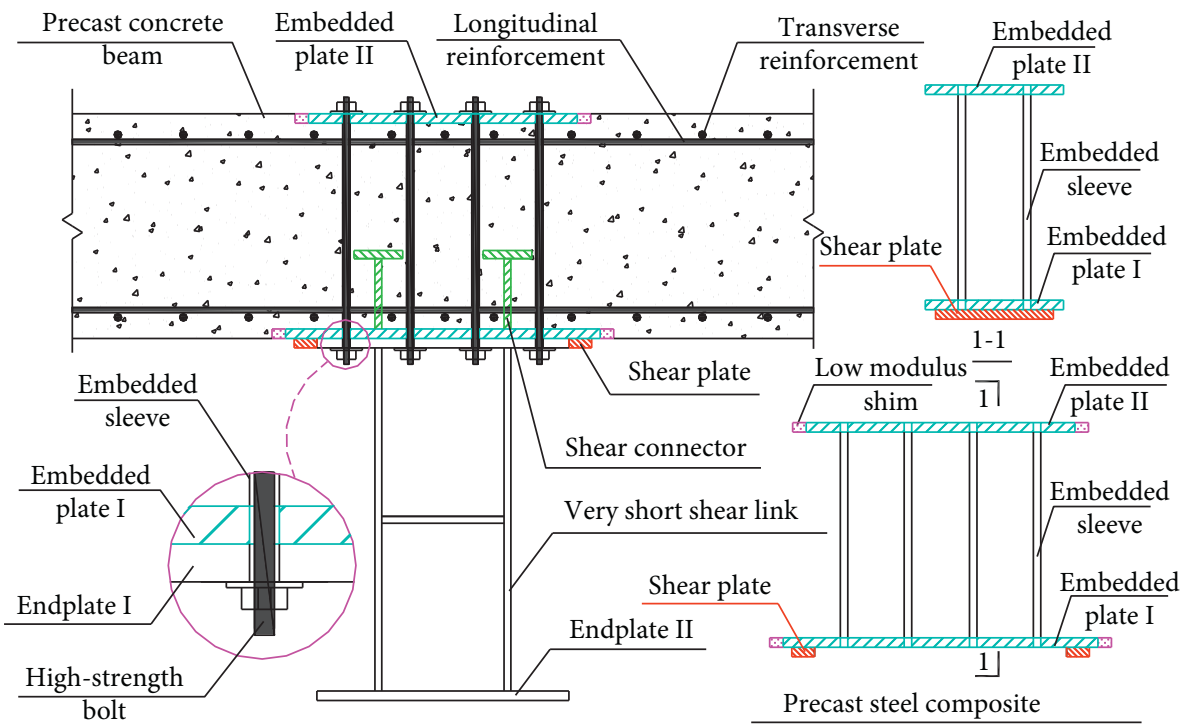

FIGURE 2: PCB-SLCC with the moment and shear force separate method.

connectors due to the smoothed surface of embedded plate I. The deformation displacement of shear connectors and precast steel composite will be quite small because of the enough shear capacity of the two shear connectors, which is less than the thickness of low modulus material at the end of embedded plate I and embedded plate II. In addition, the low modulus material can effectively prevent the longitudinal contact of embedded plate and concrete, and the damage of concrete in the precast beam will be successfully avoided. Therefore, there will be no contact in the surface between high-strength bolts and the embedded sleeve, and the highstrength bolts can only bear the bending moment. In this way, the innovative PCB-SLCC with high bearing capacity, ease of installation, and seismic resilience capacity may achieve the separation of the bending moment and shear force.

\section{Numerical Model Validation}

To guarantee the reliability of seismic performance of the innovative composite connections, the numerical analysis method of very short shear link and shear connector will be firstly validated by using ABAQUS.
3.1. Very Short Shear Link. The plastic shear bearing capacity, $V_{p}$, of a very short shear link can be written as follows [9]:

$$
V_{y}=V_{p}=0.58 f_{y w} h_{w} t_{w}
$$

A new numerical model to predict the ultimate shear strength $V_{u}$ of a very short shear links was developed through the numerical fitting method [10], which considered the effects of web-ultimate-to-shear-strength ratio, lengthto-stiffener-spacing ratio, flange-to-web-area ratio, and flange-to-web-strength ratio. The new model is given by the following equation:

$$
V_{u}=\frac{0.58 f_{u w} h_{w} t_{w}+\left(3 f_{u w} b_{f} t_{f}^{2}+1.8 f_{u w} b_{f} t_{s}^{2}\right)}{l},
$$

where $f_{y w}$ and $f_{u w}$ are the yield strength and ultimate shear strength of the web, $h_{w}$ and $t_{w}$ are the depth and thickness of the web, $b_{f}$ and $t_{f}$ are the width and the thickness of the flange, $t_{s}$ is thickness of the stiffener, and $l$ is the length of the very short shear link.

The elastic stiffness calculated value, $K_{c}$, of a very short shear link can be determined by the following equation [9]: 


$$
K_{c}=\frac{1}{1 / k_{f}+1 / k_{s}},
$$

where $k_{f}$ is the bending stiffness of the very short shear link, $k_{f}=12 E I / e^{3}, k_{s}$ is the shear stiffness of the very short shear link, $k_{s}=G A w / e e$, and $E, G, I$, and $A_{w}$ are elastic modulus, shear modulus, inertia moment, and cross-sectional area of the web of the very short shear link, respectively.

The relationship of shear force $V$ and end bending moment $M$ of a very short shear link should satisfy the following equation:

$$
M=\frac{1}{2} V l
$$

The accuracy of the numerical analysis model for very short shear link was investigated using specimen Q11, as proposed by Ji et al. [9]. The numerical model was developed using ABAQUS, and the three-dimensional eight-node reduced integration element (C3D8R) was selected to model the very short shear link. Both kinematic hardening and isotropic hardening were used to account for the strain hardening effect, and steel yielding was modeled by means of the von Mises yield criteria. The section for Q11 is $\mathrm{H} 400 \times 180 \times 10 \times 14$, the very short shear link length of Q11 was $660 \mathrm{~mm}$, and the corresponding length ratio was 0.97 . The stiffener spacing in both specimens was $220 \mathrm{~mm}$, and the stiffeners were located on both sides of the web. Q235 was assigned to the web and stiffeners of Q11, and Q345 steel was assigned to the flanges of Q11, respectively. The yield strength and ultimate strength of Q235 were $273 \mathrm{MPa}$ and $416 \mathrm{MPa}$, respectively, while the yield strength and ultimate strength of Q345 were $319 \mathrm{MPa}$ and $479 \mathrm{MPa}$, respectively.

In the numerical analysis, a reasonable boundary condition and loading protocol were very important to the performance of a very short shear link. The boundary condition in the present research was the same as the experimental test by Ji et al. [9]. As can be seen in Figure 3, one endplate was completely fixed, and the other endplate was free to translate in the vertical and horizontal translation, while the out of vertical-to-horizontal plane was restrained. In addition, the load was applied by imposing a horizontal displacement. In this way, shear forces and end bending moments with no axial force can load on the very short shear link.

The loading protocol of AISC 341 [19] was selected to carry out the numerical analysis. The loading protocol controls the rotation angle, which was computed as the relative displacement applied at the free end of the very short shear links by Ji et al. [9]. The loading displacement was divided into $1-10$ steps, from zero to $\pm 0.0025 l, \pm 0.005 l$, $\pm 0.01 l, \pm 0.03 l, \pm 0.05 l, \pm 0.07 l, \pm 0.09 l, \pm 0.11 l, \pm 0.13 l$, and $\pm 0.15 l$, while \pm indicates back and forth displacement.

The shear force versus inelastic rotation curve of specimen Q11 obtained from the test result and the numerical result is shown in Figure 4. The maximum shear forces observed in the test result, numerical result, and equation (2)'s result for Q11 are 1107, 1092, and $1100 \mathrm{kN}$, respectively, with corresponding overstrength factors of 1.87, 1.85, and 1.86 , respectively, and errors of $1.1 \%$ and $0.6 \%$ compared with the test result. In addition, the elastic stiffness results of the test, numerical, and equation (3) are $309 \mathrm{kN} \cdot \mathrm{mm}^{-1}$, $351 \mathrm{kN} \cdot \mathrm{mm}^{-1}$, and $336 \mathrm{kN} \cdot \mathrm{mm}^{-1}$, respectively.

Owing to the neglect effect of residual stress and low cycle fatigue in the numerical analysis, the maximum stress position of Q11 in weak areas will be the first to produce damage. As shown in Figure 5, the development of flange-toendplate weld fracture caused the failure of the Q11 in the test. The maximum stress of Q11 in the numerical analysis is concentrated between the flange-to-endplates at the same ultimate displacement, which is consistent with the test result.

By comparing the hysteresis curve, overstrength, elastic stiffness, and failure mode of specimen Q11 in the test, numerical, and theory results, it can be seen that the numerical analysis method is available to reflect the mechanical property of the very short shear link.

3.2. Shear Connector. Six push-out shear connectors divided into two groups were designed and tested by Xu et al. [20], and specimen QT1 was selected to analyze and validate the numerical analysis method, as shown in Figure 3(a). The test model consisted of studs, $\mathrm{H}$-section steel, longitudinal and transverse reinforcement, and concrete slab. Nine studs were laterally welded on each flange in $\mathrm{H}$-section steel. The stud diameter and height were, respectively, $13 \mathrm{~mm}$ and $80 \mathrm{~mm}$, the spacing was $80 \mathrm{~mm}$, the yield strength was $400 \mathrm{MPa}$, and ultimate strength was $480 \mathrm{MPa}$. The section for $\mathrm{H}$-section steel was $\mathrm{H} 240 \times 300 \times 20 \times 20$, and the steel material was Q345 steel with a length of $500 \mathrm{~mm}$, yield strength of $338 \mathrm{MPa}$, and ultimate strength of $578 \mathrm{MPa}$. The longitudinal reinforcement diameter was $8 \mathrm{~mm}$, and the spacing was $80 \mathrm{~mm}$. The transverse reinforcement diameter was $6 \mathrm{~mm}$, and the spacing was $80 \mathrm{~mm}$. The yield strength and ultimate strength of longitudinal and transverse reinforcement were, respectively, $338 \mathrm{MPa}$ and $421 \mathrm{MPa}$, the elastic modulus was $20800 \mathrm{MPa}$, and Poisson's ratio was 0.3 . In addition, both kinematic hardening and isotropic hardening were also used to account for the steel strain hardening effect, and steel yielding was modeled by means of the von Mises yield criteria. The thickness, height, and width of concrete slab were $100 \mathrm{~mm}, 500 \mathrm{~mm}$, and $450 \mathrm{~mm}$, respectively. The concrete material was C50 grade of concrete with a compressive strength of $23.1 \mathrm{MPa}$, tensile strength of 1.89 MPa, elastic modulus of $34500 \mathrm{MPa}$, and Poisson's ratio of 0.2 .

Due to the boundary and loading symmetry of specimen QT1 in the push-out analysis, only a quarter part of the QT1 model was simulated instead of the whole model, as shown in Figure 6(b). In the numerical model, the H-section steel and studs were created in the same part, while the concrete slab and rebar composited by longitudinal reinforcement and transverse reinforcement were created by different parts. The two-node three-dimensional truss element (T3D2) was introduced to simulate the embedded longitudinal and transverse reinforcements, while the C3D8R element was used to simulate $\mathrm{H}$-section steel, concrete, and studs. To properly consider the interaction effect of steel and concrete, 


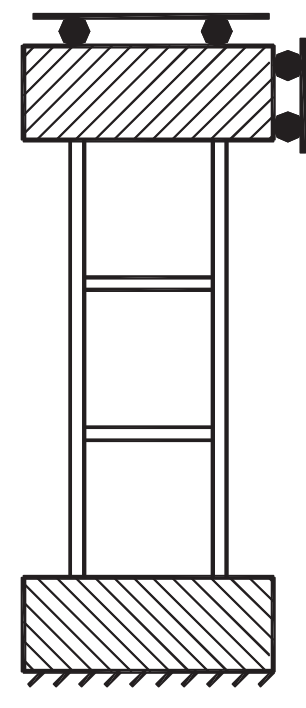

(a)

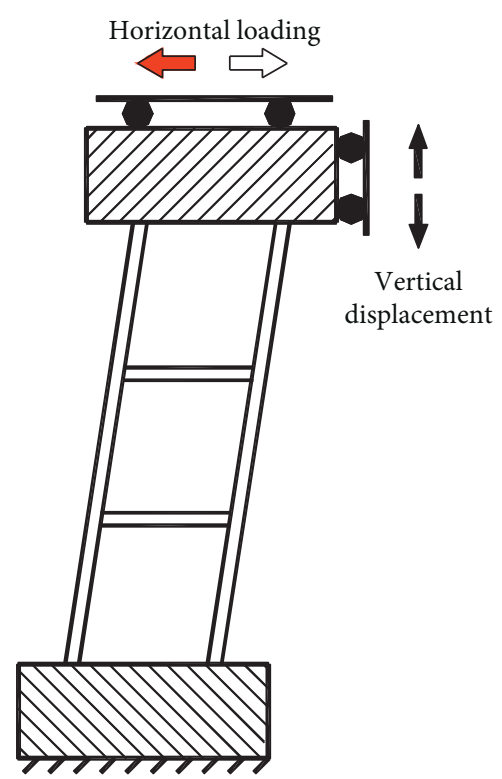

(b)

FIGURE 3: Boundary conditions applied to very short shear link: (a) initial configuration; (b) deformed configuration.

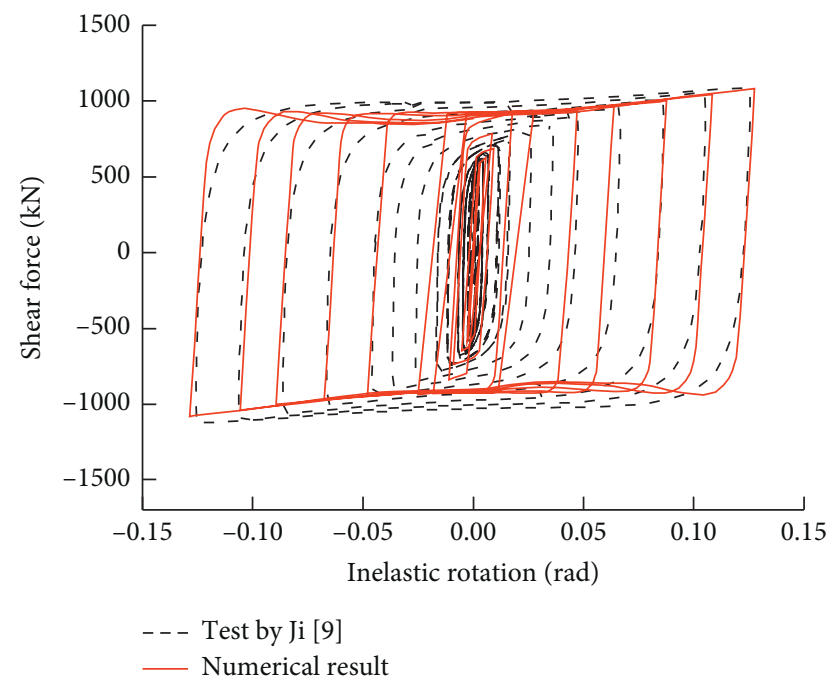

FIgURE 4: Shear forces versus inelastic rotation for Q11.

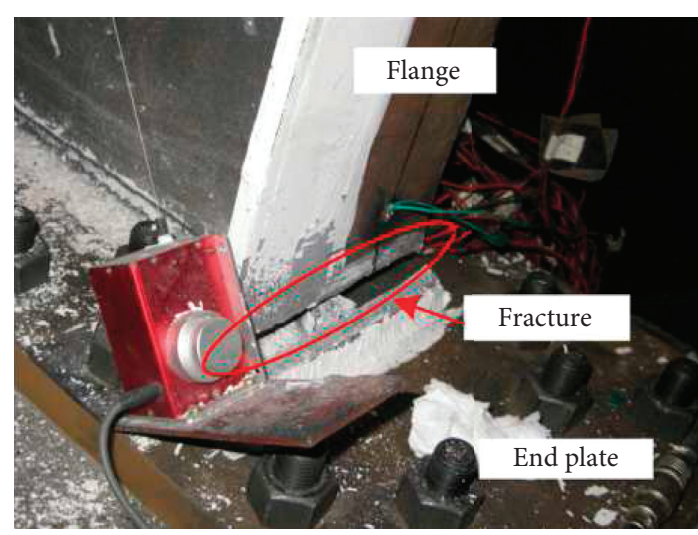

(a)

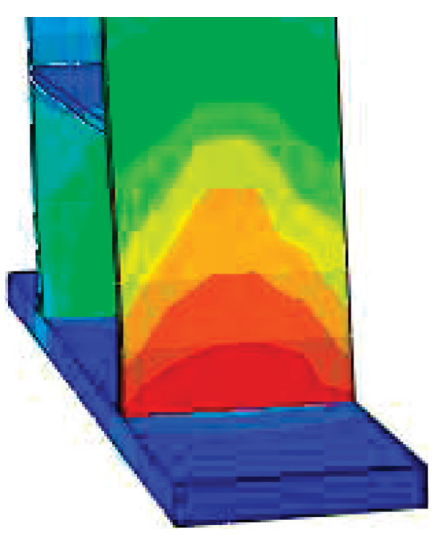

(b)

Figure 5: Analyzed failure of specimen: (a) test result [9]; (b) numerical result. 


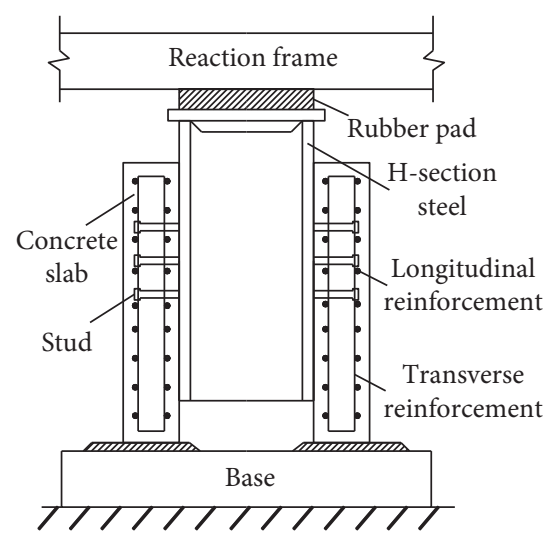

(a)

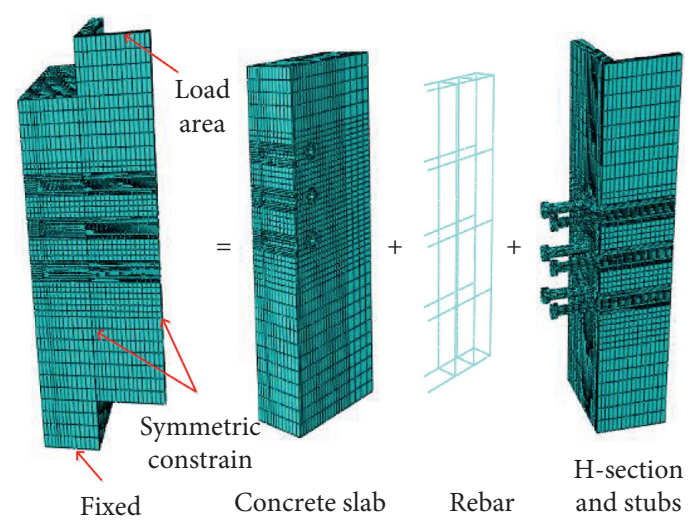

(b)

Figure 6: Schematic of shear studs: (a) test model; (b) numerical model.

three surface-to-surface contacts including stud-to-concrete contact, $\mathrm{H}$ section-to-concrete contact, and rebar-to-concrete contact were established. Contact properties were defined along both the normal direction and tangential direction, and the hard contact was defined in the normal direction, while the friction coefficient 0.3 was employed in the tangential direction [20]. In addition, the nodes at the bottom of the concrete slab were restrained from all of the three directions, and the symmetry boundary conditions were applied to the two symmetric surfaces. The quasistatic loading with a rate of $0.2 \mathrm{~mm} / \mathrm{s}$ was applied at the top of $\mathrm{H}$-section steel [20].

During the numerical analysis of shear connectors, large deformation and complicated contact can be effectively modeled and analyzed by using the dynamic explicit analysis in ABAQUS [21]. Figure 7 shows load-slip curves of the test and numerical analysis results related to specimen QT1. The elastic stiffness of both curves at the initial stage is basically the same, and the ultimate load of the numerical result is slightly smaller than the test value; this can be explained by the difference of friction and bonding effect in the contact surfaces of steel and concrete. The verification numerical result almost agrees with the test results, and the inaccurate simulation will not affect the numerical analysis results.

The comparison between the concrete damage zone obtained by the test and those obtained by the numerical analysis of specimen QT1 is shown in Figure 8(a). The general damage zone of the concrete slab in the direction of cross section is in a triangular shape, and the continuous damage zone in the contact surface of $\mathrm{H}$-section steel and concrete slab appears in a rectangle, which is the same as that found in the test result. In addition, the maximum damage value of concrete slab has reached $98.2 \%$. The failure modes and Mises stress distribution of a single stud are shown in Figure 8 (b). The damage value of stud influenced by the shear force is $98.0 \%$, and the fracture location of stud for test and numerical results is at the inner surface of $\mathrm{H}$-section steel and the stud. The maximum von Mises stress location appears in the halfway of the stud, which has moved away from the stud root, and the maximum stress is $433 \mathrm{MPa}$,

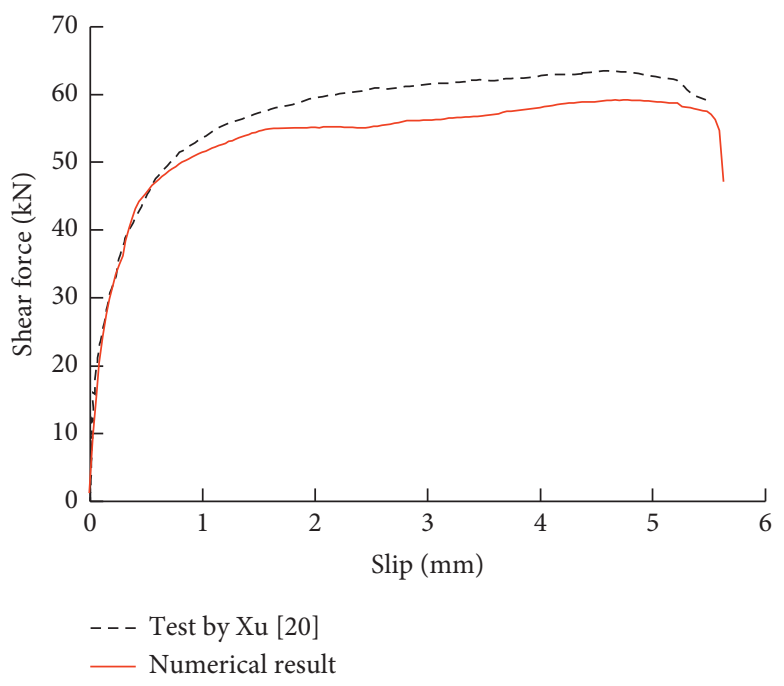

FIgURE 7: Load-slip curves of shear studs.

which is less than the yield strength of $480 \mathrm{MPa}$, so the shear failure of the stud only occurs at the stud root.

By comparing the load-slip curve and damage modes of concrete and studs of specimen QT1 in the test and numerical results, it has been proved that the above numerical method can effectively evaluate the shear capacity and failure modes of shear connectors.

\section{Mechanical Properties of Shear Connectors}

Since the shear force of PCB-SLCC transferred from the very short shear link will be only carried by the shear connectors, the traditional T-type perfobond rib shear connectors [22], shear studs [23], and Y-type perfobond rib shear connectors [24] may not satisfy the capacity requirement of shear force. Based on the mechanical characteristic and working principle of PCB-SLCC, three shear connectors of linear type, cross type, cross bilinear type (CB type), and channel type [25] arranged on an extension of the two flanges of the very short shear link are developed, as shown in Figure 9. 


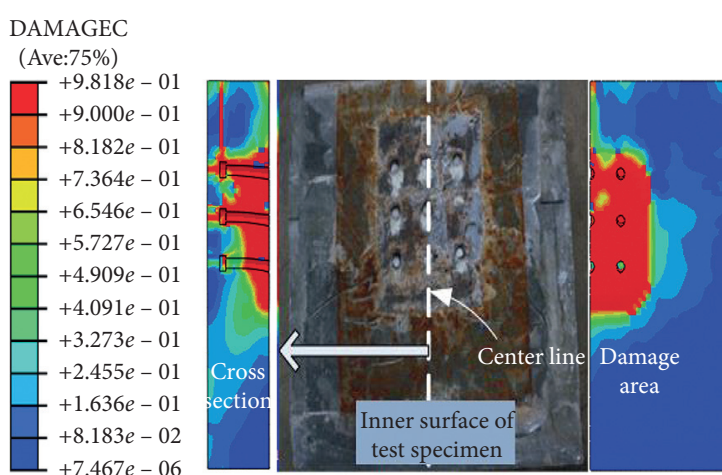

(a)

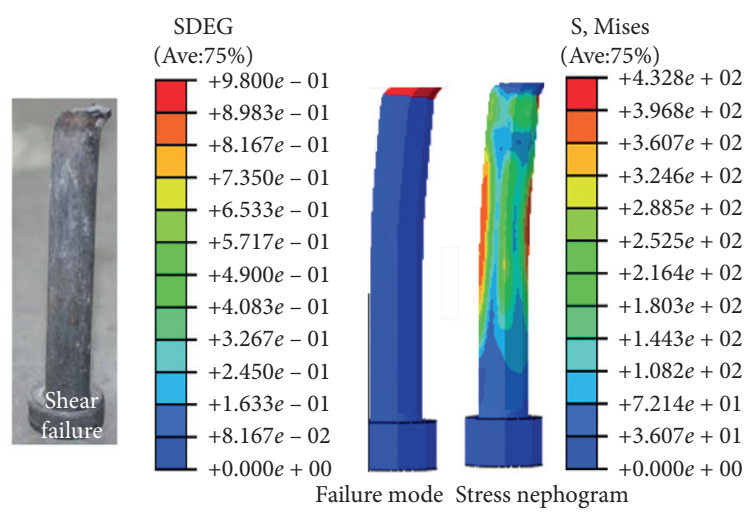

(b)

FIGURE 8: Analyzed failure of concrete and shear studs: (a) concrete damage; (b) stud damage and stress nephogram.

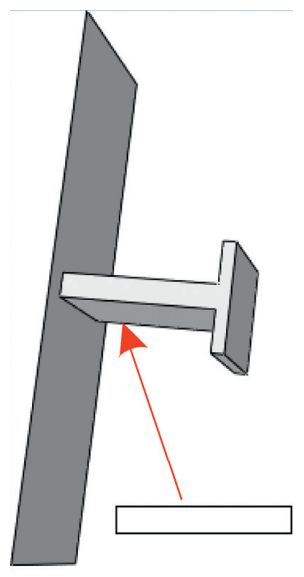

(a)

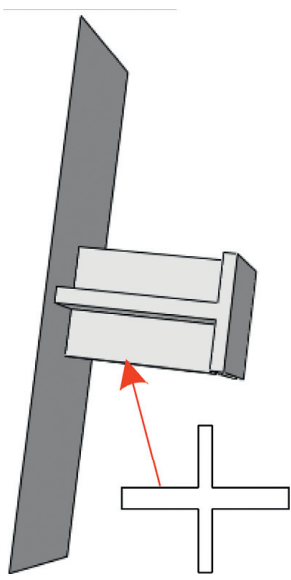

(b)

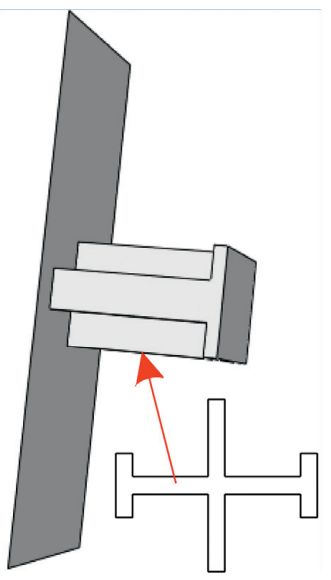

(c)

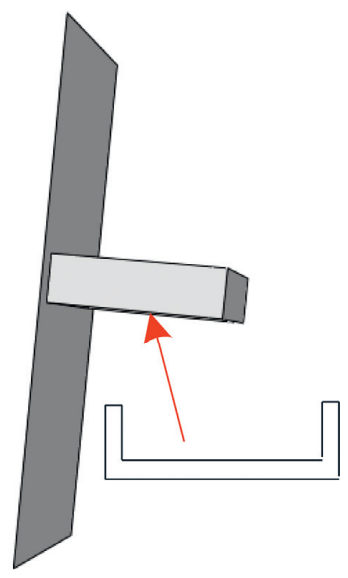

(d)

FIGURE 9: Shear connector configurations: (a) linear type; (b) cross type; (c) cross bilinear type (CB type); (d) channel type.

4.1. Numerical Analysis Method of Shear Connectors. In light of the boundary condition, geometrical size, and loading mode of the push-out specimens, a half part of the specimens was simulated to reflect the mechanical properties of the shear connectors, as shown in Figure 10. The sections for $\mathrm{H}$-section steel in model-1, model-2, model-3, and model-4 are all $\mathrm{H} 250 \times 250 \times 16 \times 20$, and the sections for three kinds of shear connectors with the same cross-sectional area are shown in Table 1. The steel material of $\mathrm{H}$-section steel and shear connectors is Q345 steel with a yield strength of $319 \mathrm{MPa}$ and ultimate strength of $479 \mathrm{MPa}$, while the $\mathrm{H}$-section steel and shear connectors are connected by welding. The section of precast concrete beam is $250 \mathrm{~mm} \times 400 \mathrm{~mm} \times 590 \mathrm{~mm} \quad(X, Y, Z$ direction, respectively), and the concrete material is $\mathrm{C} 30$ grade with an elastic modulus of $30000 \mathrm{MPa}$, compressive strength of $14.3 \mathrm{MPa}$, tensile strength of $1.43 \mathrm{MPa}$, and Poisson's ratio of 0.2 [26]. The longitudinal reinforcement diameter is $12 \mathrm{~mm}$, and the reinforcement ratio is $1.3 \%$. The transverse reinforcement diameter is $8 \mathrm{~mm}$, and the reinforcement ratio is $0.65 \%$. The yield strength and ultimate strength of longitudinal and transverse reinforcements are, respectively, $338 \mathrm{MPa}$ and
$421 \mathrm{MPa}$, the elastic modulus is $20800 \mathrm{MPa}$, and Poisson's ratio is 0.3 . In the numerical analysis model, C3D8R element is introduced to simulate the shear connectors, H-section steel, and concrete while T3D2 element is used to simulate embedded reinforcement, and both kinematic hardening and isotropic hardening are used to account for the steel strain hardening effect, and steel yielding is modeled by means of the von Mises yield criteria.

In the numerical analysis, the contact surfaces between precast concrete beam and shear connector and between precast concrete beam and $\mathrm{H}$-section are simulated by the contact properties along the normal and tangential directions, which define hard contact in the normal direction and assume the coefficient of friction 0.4 and 0 [21], respectively, for both contact surfaces in the tangential direction. The nodes at the bottom of the precast concrete beam are restrained from all of the three directions, and the symmetry boundary condition is applied at the $X Z$ surface, as shown in Figure 10. The load applied during the test is simulated by applying a rate of $0.2 \mathrm{~mm} / \mathrm{s}$ displacement controlled at the top of H-section steel, the same as the loading protocol of specimen QT1 described in Section 3.2 [20]. 


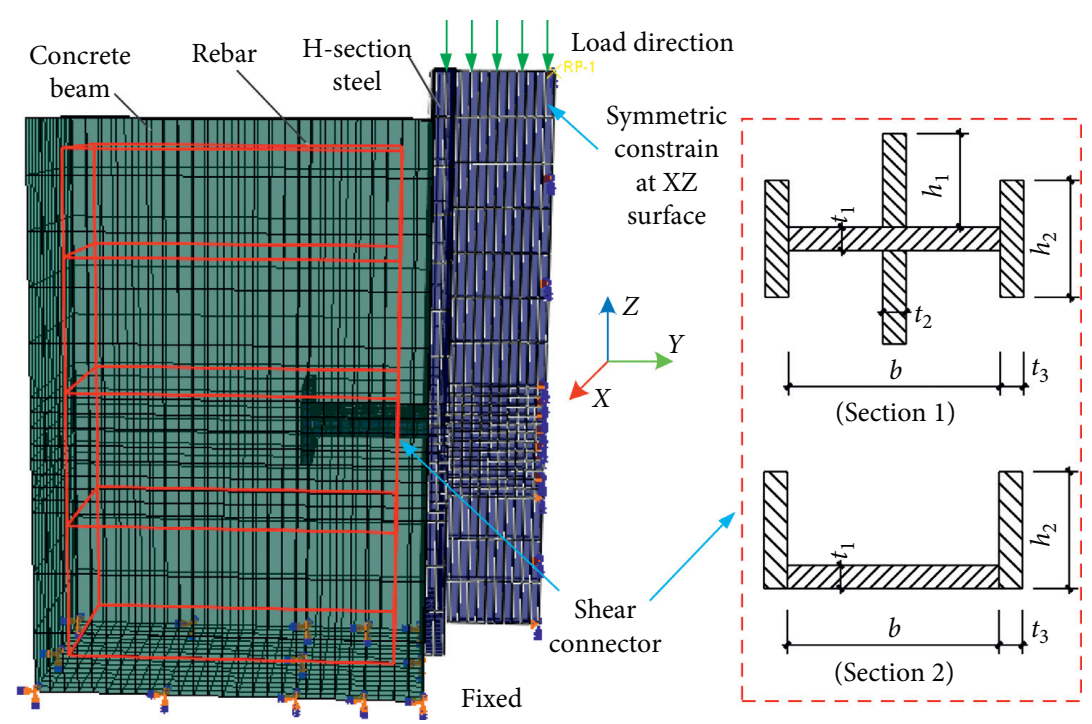

FIGURE 10: FE model of shear connectors.

TABLE 1: Parameters of shear connectors.

\begin{tabular}{|c|c|c|c|c|c|c|c|c|c|}
\hline Model & Section & $\begin{array}{c}\text { Shear } \\
\text { connector }\end{array}$ & $t_{1}$ & $t_{2}$ & $t_{3}$ & $b$ & $h_{1}$ & $h_{2}$ & $\begin{array}{c}\text { Area } \\
A\end{array}$ \\
\hline Model-1 & Section-1 & Linear type & 18 & 0 & 0 & 96 & 0 & 0 & \\
\hline Model-2 & Section-1 & Cross type & 12 & 8 & 0 & 96 & 36 & 0 & \\
\hline Model-3 & Section-1 & $\mathrm{CB}$ type & 8.4 & 8 & 8 & 80 & 36 & 30 & 1728 \\
\hline Model-4 & Section-2 & $\begin{array}{l}\text { Channel } \\
\text { type }\end{array}$ & 12 & 0 & 8 & 96 & 0 & 36 & \\
\hline
\end{tabular}

Note. $t_{1}$ : horizontal plate thickness; $t_{2}$ : middle vertical plate thickness; $t_{3}$ : end vertical plate thickness; $b$ : horizontal plate length; $h_{1}$ : middle vertical plate height; $h_{2}$ : end vertical plate height; $A$ : cross-sectional area.

\subsection{Shear Capacity of Shear Connectors. Figure 11 shows the} load-slip curves from numerical analysis results, respectively, related to the linear-type, cross-type, CB-type, and channel-type shear connectors. Compared to numerical results of those shear connectors, the load-slip curves are basically the same in the elastic stage; it can be explained by the same cross-sectional area of those connectors and the elastic of concrete and connectors. As the load increases, all the above shear connectors enter into the plastic state, and the ultimate loads of linear-type, cross-type, CB-type, and channel-type shear connectors at $\mathrm{B}_{1}, \mathrm{~B}_{2}, \mathrm{~B}_{3}$, and $\mathrm{B}_{4}$ are $349.5 \mathrm{kN}, 315.8 \mathrm{kN}, 378.8 \mathrm{kN}$, and $311.8 \mathrm{kN}$ at the slip displacement of $1.40 \mathrm{~mm}, 1.55 \mathrm{~mm}, 2.25 \mathrm{~mm}$, and $2.44 \mathrm{~mm}$, respectively. In addition, the load-slip curves of those shear connectors have been declining since the ultimate load, and the curves of cross-type and CB-type shear connectors decrease at a more subdued pace than the curve of lineartype and channel-type shear connectors when they reach the ultimate load.

The von Mises stress nephograms of linear-type, crosstype, CB-type, and channel-type shear connectors at the ultimate load are shown in Figure 12. As can be observed, the stress of linear-type shear connector is uniformly distributed and simultaneously yielded throughout the linear plate and then reaches the ultimate value of $347 \mathrm{MPa}$. However, the stresses of cross-type shear connector in horizontal and vertical directions are completely different. The greatest stress is found at the location of the vertical plate, with an ultimate stress value of $394 \mathrm{MPa}$, while the maximum stress value on the horizontal plate is $230 \mathrm{MPa}$. The cross-type shear connector cannot reach and retain the full section yield under the quasistatic load, and the average stress value of the cross-type shear connector is almost $312 \mathrm{MPa}$, which is less than the stress value of linear-type shear connector. This can explain why the ultimate load value $B_{2}$ is smaller than the value $B_{1}$. The maximum stresses of $C B$-type shear connector value in the middle vertical plate, horizontal plate, and end vertical plate are $427 \mathrm{MPa}, 288 \mathrm{MPa}$, and $392 \mathrm{MPa}$, below the ultimate strength value of $479 \mathrm{MPa}$, and the average stress value of the CB-type shear connector is approximately $382 \mathrm{MPa}$. The maximum stresses of channel-type shear connector value in the middle horizontal plate and end vertical plate are $410 \mathrm{MPa}$ and $310 \mathrm{MPa}$, and the average stress value is about $343 \mathrm{MPa}$. As expected, the ultimate load of CB-type shear connector is greater than the other three shear connectors, due to the larger average stress.

Figure 13 compares the damage nephogram of concrete beam at $B_{1}, B_{2}, B_{3}$, and $B_{4}$ obtained in the numerical analysis. The stress concentration occurs at the contact area between the shear connectors and concrete beam; then, the concrete near the contact surface will be seriously damaged. The greatest damage of concrete corresponding to the concrete fracture near the linear-type shear connector in model-1 is $90.2 \%$, which appears at the end of linear-type shear connector. The damage concrete value between cross-type shear connector and precast concrete beam in model-2 has reached $90.6 \%$, and the damage zone and damage value are both larger than those in model-1, which have caused the fall in the average shear stress and ultimate shear force. After two vertical plates are arranged at the left end and right end of the horizontal plate in model-3, the contact area and corresponding ultimate load can be effectively increased, despite increasing the concrete damage value to $94.8 \%$. The damage concrete value between channel-type shear 


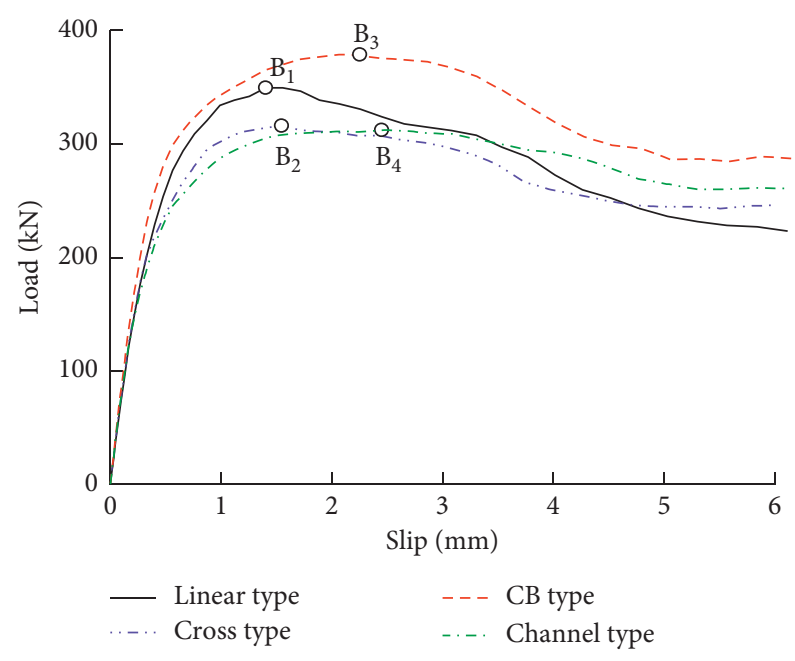

FIGURE 11: Load-slip curves of shear connectors.

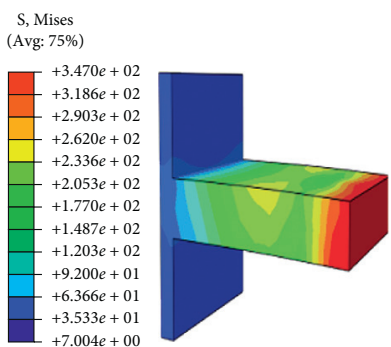

(a)

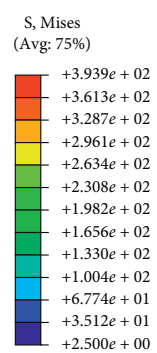

$+2500 e+00$

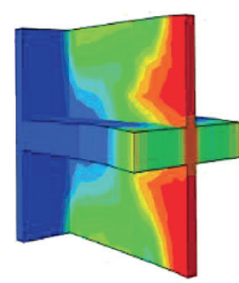

(b)

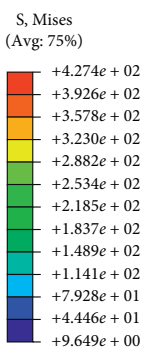

$+9.649 e+00$

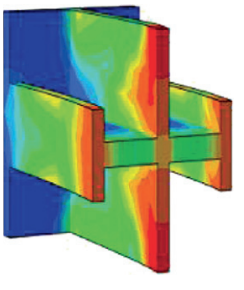

(c)

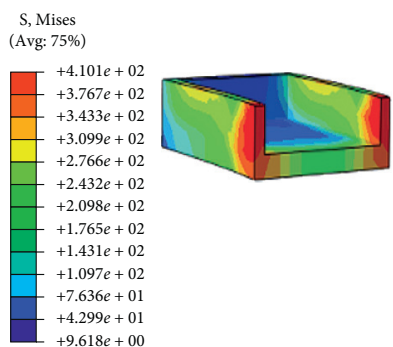

(d)

Figure 12: von Mises stress nephogram of shear connectors: (a) linear type; (b) cross type; (c) cross bilinear type (CB type); (d) channel type.

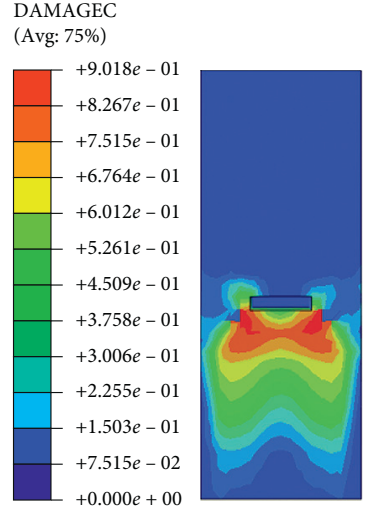

(a)

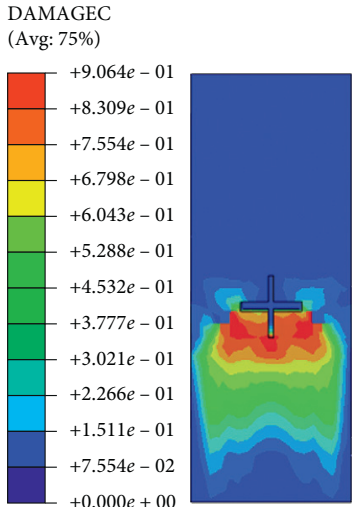

(b)

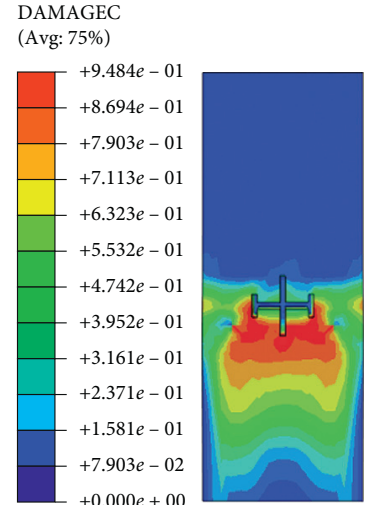

(c)

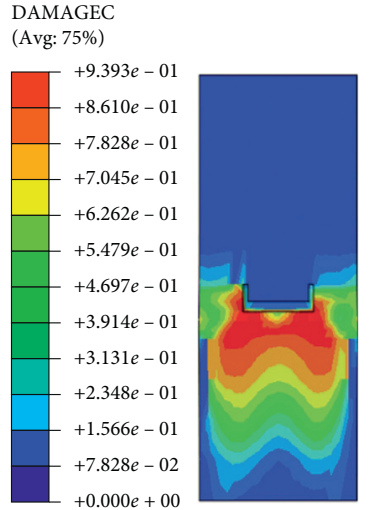

(d)

Figure 13: Damage nephogram of concrete: (a) $\mathrm{B}_{1}$; (b) $\mathrm{B}_{2}$; (c) $\mathrm{B}_{3}$; (d) $\mathrm{B}_{4}$.

connector and precast concrete beam in model-4 has reached $93.9 \%$, and the damage zone and damage value are both larger than those in model-2 at almost the same ultimate load. Among the mentioned three analysis cases, the damage zone and damage value of model- 3 will be the least when those models have reached the same load value.
Compared with those three shear connectors in this numerical analysis, the CB-type shear connector can significantly enhance the ultimate load and reduce the concrete damage under quasistatic loading, so the CB-type shear connector will be highly recommended to be used in the PCB-SLCC. 


\section{Seismic Performance of the Innovative PCB-SLCC}

The behavior of very short shear link and shear connectors in the experimental analysis was predicted accurately though numerical analysis. Five numerical analysis models considering the influencing parameters of concrete strength, shear connector length, end vertical plate height, and highstrength bolt spacing are analyzed to accurately investigate the mechanical property and working principle of PCBSLCC with CB-type shear connectors by using a verified numerical method.

5.1. Numerical Analysis Model and Method of PCB-SLCC. The numerical specimens of PCB-SLCC are shown in Figure 14. The sections of precast concrete beam in PCB-SLCC specimens are all based on $250 \mathrm{~mm} \times 400 \mathrm{~mm} \times 2000 \mathrm{~mm}$, and the distribution of longitudinal and transverse reinforcements is the same as the precast concrete beam described in Section 4.1. The very short shear link in PCBSLCC models is based on a section of $\mathrm{H} 200 \times 150 \times 6 \times 8$, and the length and corresponding length ratio are $400 \mathrm{~mm}$ and 0.72 , respectively. The stiffener spacing and stiffener thickness in all specimens are $100 \mathrm{~mm}$ and $10 \mathrm{~mm}$, respectively, and Q235 steel is assigned to the web and stiffeners, while Q345 steel is assigned to the flanges. The sizes of endplate I, endplate II, and embedded plate II are all $250 \mathrm{~mm} \times 400 \mathrm{~mm}$, and the size of embedded plate I in PCBSLCC-1 through PCB-SLCC-4 and PCB-SLCC-5 is $250 \mathrm{~mm} \times 540 \mathrm{~mm}$ and $250 \mathrm{~mm} \times 570 \mathrm{~mm}$, respectively, which are all based on Q345 steel. In addition, the thicknesses of these plates are $20 \mathrm{~mm}$, and the diameters of the bolt holes and high-strength bolts are $22 \mathrm{~mm}$ and $20 \mathrm{~mm}$, respectively. The material properties of Q235 steel and Q345 steel have been described in Section 3.1, and the yield strength and ultimate strength of M20 high-strength bolts are $940 \mathrm{MPa}$ and $1040 \mathrm{MPa}$ [27], respectively.

Table 2 shows the parameters of the PCB-SLCC specimens, while $L$ is the shear connector length, and other parameters are shown in Table 1 . Specimens PCB-SLCC-1 and PCB-SLCC-2 have regular bolt spacing and same shear connector parameters but different concrete strength; PCBSLCC-1 and PCB-SLCC-3 have regular bolt spacing and same concrete strength but different shear connector lengths; PCB-SLCC-1 and PCB-SLCC-4 have regular bolt spacing and same concrete strength, but different endplate heights. In addition, the model PCB-SLCC-5 of a corresponding shear connector and precast concrete beam is designed for a comparison of regular and special bolt spacing, as shown in Figure 14. The material properties of C30 and C50 concrete have been described in Section 4.1.

During the numerical analysis, the T3D2 element is used to simulate the embedded rebar, while the C3D8R element is also introduced to simulate the other components. Contact coefficient of friction between precast concrete beam and embedded plate II with the tangential direction is zero, and the contact property between embedded plate II and shear plate is defined along both the tangential direction with friction coefficient 0.3 . Other contact properties are defined the same as the contact properties described in Section 4.1. As can be seen in Figure 14, embedded plate II is completely fixed, and the precast concrete beam is free to translate in the vertical and horizontal translation, while the out of verticalto-horizontal plane is restrained. The load is applied by imposing a horizontal displacement, and the load protocol is the same as that of the very short shear link.

5.2. Performance Evaluation of PCB-SLCC. To reveal the mechanical properties and failure modes of the innovative PCB-SLCC, a parametric analysis is performed based on the validated numerical mode, which establishes the following numerical analysis method described previously.

5.2.1. Hysteresis Curves. Figure 15 shows the numerical results of the hysteresis curves of PCB-SLCC-1 through PCB-SLCC-5 and the corresponding very short shear link. It is observed that all the specimens have the same hysteresis curves; this behavior can be explained by the sufficient bearing capacity of PCB-SLCC-1 through PCB-SLCC-5 specimens, and the very short shear links exhibit the plastic energy dissipation capability during the cyclic loading. In addition, the ultimate shear forces for all the specimens are $378 \mathrm{kN}$ at 0.15 radians of link plastic deformation, which is close to equation (2)'s calculation value of $385 \mathrm{kN}$ [28], showing great agreement and reliability.

5.2.2. Concrete Damage. As shown in Figure 16, the maximum concrete damage values of PCB-SLCC-1 through PCB-SLCC-5 are $87.3 \%, 82.1 \%, 85.1 \%, 89.6 \%$, and $86.9 \%$, respectively, and the damage modes are basically the same, which are all along the nearest bolt hole to the end vertical plate of shear connectors. Compared with PCB-SLCC-1, the concrete damage value and damage zone of PCB-SLCC- 2 are effectively reduced by increasing the concrete strength from C30 grade to C50 grade, and increasing the shear connector length will reduce the concrete damage value by PCB-SLCC3 , but damage zone is not changed basically. However, the damage value and damage zone of PCB-SLCC-4 are increased compared with PCB-SLCC-1, while the end vertical plate height is reduced from $30 \mathrm{~mm}$ to $20 \mathrm{~mm}$; this is mainly caused by the stress concentration between the end vertical plate and precast concrete beam. The damage value is slightly reduced by using the special bolt spacing in PCB-SLCC- 5 , and the damage zone has no obvious change compared with the PCB-SLCC-1. Therefore, the most effective way to reduce the damage value and damage zone is by using the highstrength concrete; the simultaneous increase of shear connector length and bolt spacing will lead to the reduction of concrete damage, but the stress concentration phenomenon will further intensify with the decrease of the end vertical plate height. Embedded plate I and precast concrete beam separated by low modulus shims with a thickness of $2 \mathrm{~mm}$ can effectively prevent the concrete damage development in the two ends of the embedded plate. 


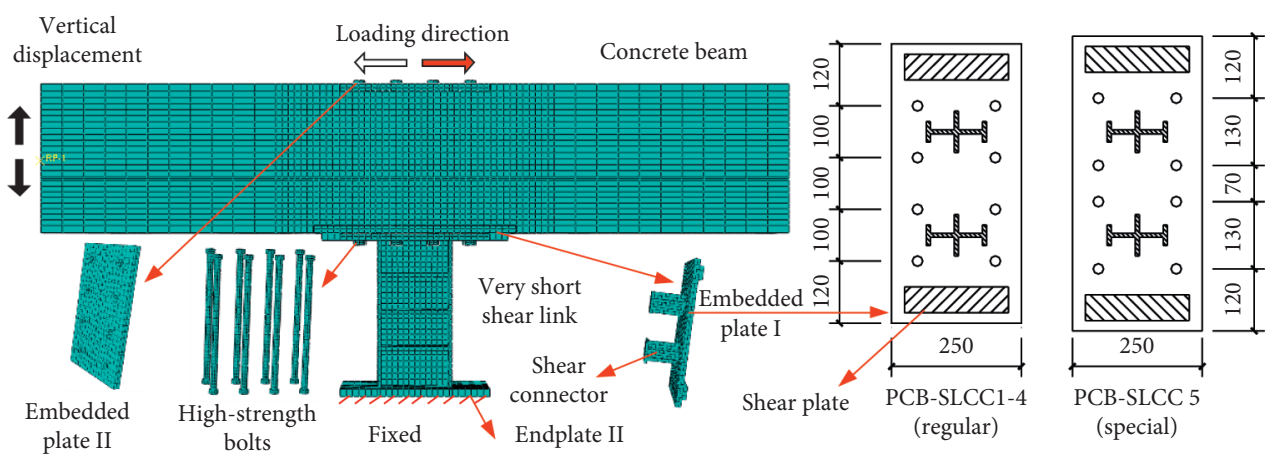

Figure 14: FE model of new composite connections.

TABLE 2: Parameters of PCB-SLCC.

\begin{tabular}{lcccccccccc}
\hline Specimen & Concrete strength & $L(\mathrm{~mm})$ & $t_{1}(\mathrm{~mm})$ & $t_{2}(\mathrm{~mm})$ & $t_{3}(\mathrm{~mm})$ & $b(\mathrm{~mm})$ & $h_{1}(\mathrm{~mm})$ & $h_{2}(\mathrm{~mm})$ & Area $A\left(\mathrm{~mm}^{2}\right)$ & Bolt spacing \\
\hline PCB-SLCC-1 & C30 & 120 & 8.4 & 8 & 8 & 80 & 36 & 30 & Regular \\
PCB-SLCC-2 & C50 & 120 & 8.4 & 8 & 8 & 80 & 36 & 30 & Regular \\
PCB-SLCC-3 & C30 & $\mathbf{1 5 0}$ & 8.4 & 8 & 8 & 80 & 36 & 30 & 1728 & Regular \\
PCB-SLCC-4 & C30 & 120 & 8.4 & 10.3 & 8 & 80 & 36 & $\mathbf{2 0}$ & Regular \\
PCB-SLCC-5 & C30 & 120 & 8.4 & 8 & 8 & 80 & 36 & 30 & Special \\
\hline
\end{tabular}

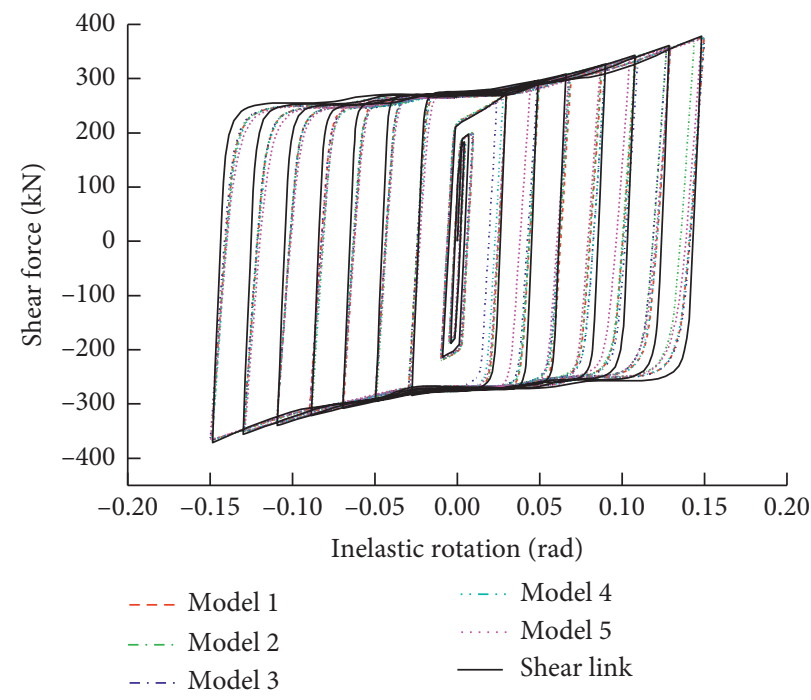

FIgURe 15: Hysteresis curves of specimens.

5.2.3. CB-Type Shear Connector Stress. The stress nephograms of CB-type shear connectors in PCB-SLCC-1 through PCB-SLCC-5 are shown in Figure 17. The stresses distribution is basically the same for all specimens, which are found at the location of the middle vertical plate and the junction of the horizontal plate and end vertical plate. The maximum stress values are $319 \mathrm{MPa}, 281 \mathrm{MPa}, 313 \mathrm{MPa}$, $292 \mathrm{MPa}$, and $319 \mathrm{MPa}$, respectively, which are all less than the yield strength of Q345 steel. Therefore, the shear connectors are still in elastic stage while the PCB-SLCCs reach the ultimate load. The stress value of PCB-SLCC-2 with C50 concrete is significantly lower than that of PCB-SLCC-1 with $\mathrm{C} 30$ concrete; this is mainly due to the precast concrete beam that has to bear more stress and load than PCB-SLCC-1. The decrease of the end vertical plate height in PCB-SLCC-4 will also reduce the shear connector stress; it is mainly caused by the serious stress concentration and concrete damage between the shear connectors and concrete, so the load of shear connector has decreased. In addition, the shear connector length and bolt spacing have no apparent difference on the stress of the shear connector, as shown by PCB-SLCC-1, PCB-SLCC-3, and PCB-SLCC-5. 


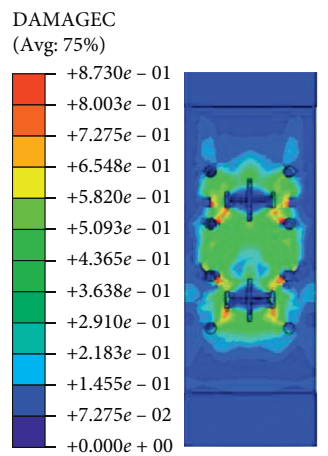

(a)

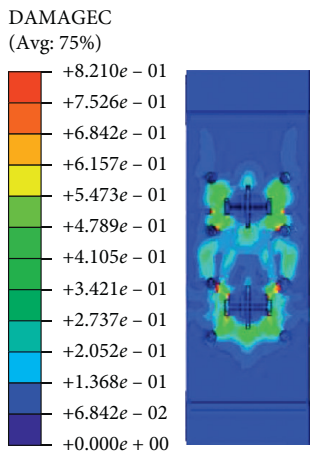

(b)

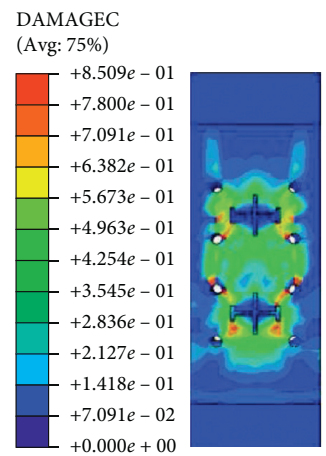

(c)

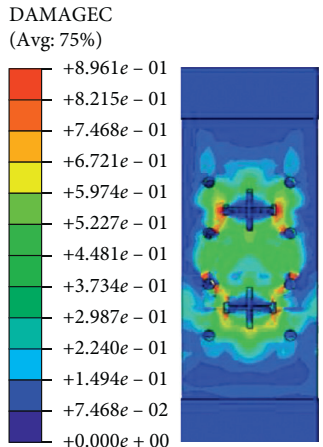

(d)

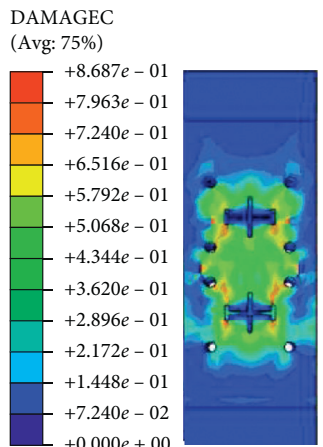

(e)

Figure 16: Damage nephogram of concrete: (a) PCB-SLCC-1; (b) PCB-SLCC-2; (c) PCB-SLCC-3; (d) PCB-SLCC-4; (e) PCB-SLCC-5.

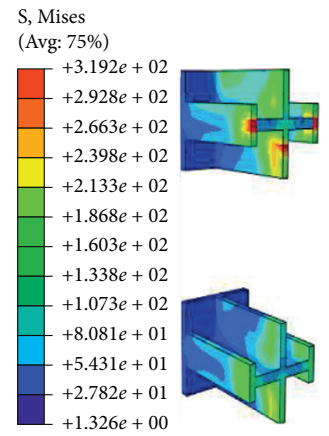

(a)

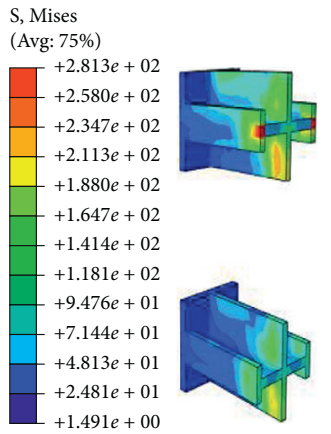

(b)

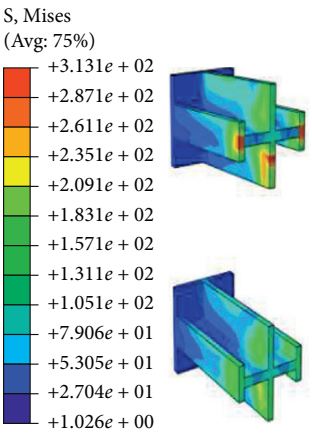

(c)

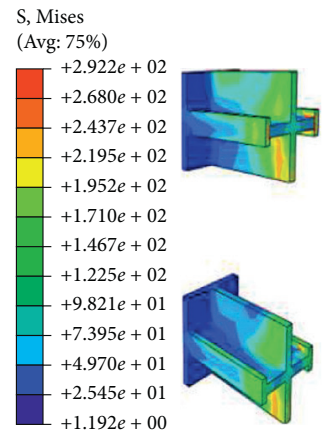

(d)

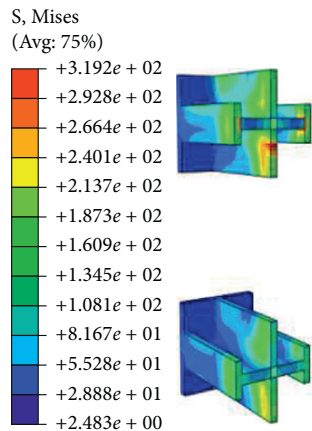

(e)

Figure 17: Stress nephogram of shear connectors: (a) PCB-SLCC-1; (b) PCB-SLCC-2; (c) PCB-SLCC-3; (d) PCB-SLCC-4; (e) PCB-SLCC-5.

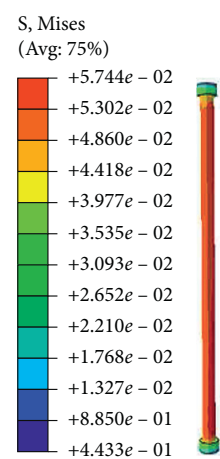

(a)

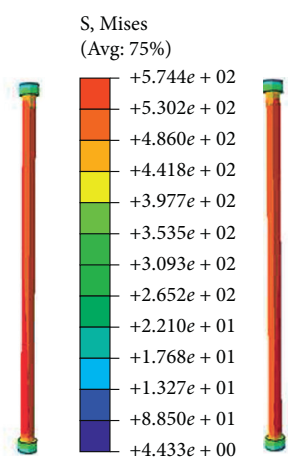

(b)

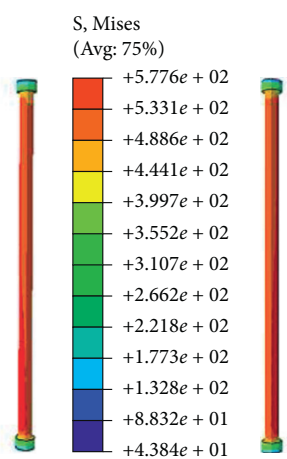

(c)

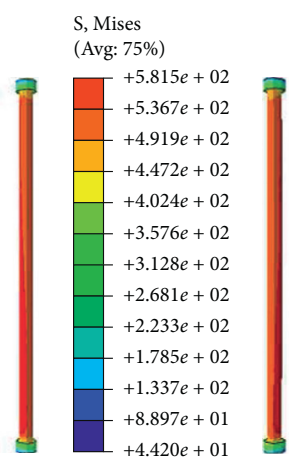

(d)

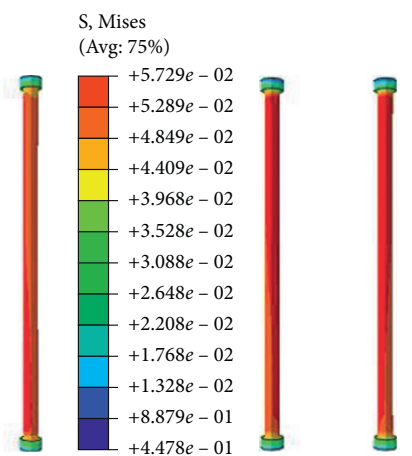

(e)

FIGURE 18: Stress nephogram of high-strength bolts: (a) PCB-SLCC-1; (b) PCB-SLCC-2; (c) PCB-SLCC-3; (d) PCB-SLCC-4; (e) PCBSLCC-5.

5.2.4. High-Strength Bolt Stress. Due to the same ultimate shear forces for all the specimens, the end bending moment that was calculated by equation (4) and transferred to the PCB-SLCC should have to be equal. According to Figure 18, the maximum stresses of the topmost high-strength bolts in PCB-SLCC-1 through PCB-SLCC-5 are $574 \mathrm{MPa}, 574 \mathrm{MPa}$, $577 \mathrm{MPa}, 582 \mathrm{MPa}$, and $573 \mathrm{MPa}$, respectively, which are less than the material yield strength of $940 \mathrm{MPa}$, and corresponding bolt tensions of PCB-SLCC-1 through PCB-SLCC-5 are $180 \mathrm{kN}, 180 \mathrm{kN}, 181 \mathrm{kN}, 183 \mathrm{kN}$, and $180 \mathrm{kN}$, respectively. Therefore, there are no remarkable changes in the bolt tensions while the main parameters of PCB-SLCC are adjusted. As expected, it indicates that the bending moment is not related to the shear force by using the proposed PCB-SLCC. 


\section{Conclusions}

To investigate the mechanical properties and failure modes of an innovative PCB-SLCC, four different types of shear connectors were firstly designed and analyzed, and then five PCB-SLCC specimens with ideal shear connectors were parametrically studied. The parameters include concrete strength, shear connector length, endplate height, and high-strength bolt spacing. Based on the typical numerical analysis, the reliability of the parametrical analysis was confirmed, and the following conclusions could be drawn:

(1) Compared with the linear-type, cross-type, and channel-type shear connectors, the CB-type shear connector can significantly enhance the ultimate shear capacity and reduce the slip displacement during the push-out analysis, and it is recommended to be used in the PCB-SLCC.

(2) As the very short shear link reaches the ultimate shear capacity, the proposed PCB-SLCC can have enough bearing capacity, while the CB-type shear connector and high-strength bolts can always be in the elastic stage with no yield or damage.

(3) The maximum concrete damage value between embedded plate II and precast concrete beam in PCB-SLCC is appropriately $89.6 \%$, which occurs mainly along the nearest bolt hole to the end vertical plate of shear connector, and the most effective way to further reduce the damage value and damage zone is by using high-strength concrete.

(4) In the innovative PCB-SLCC, the CB-type shear connector will only bear the shear force, and the bending moment is only carried by the high-strength bolts, so the shear force and bending moment can be effectively separated, which expresses the characteristics of high bearing capacity, ease in installation, and seismic resilience capacity.

Based on the present research and numerical analysis results, the seismic performance of the innovative PCBSLCC can be preliminarily revealed, which can provide a reference for further experimental tests. This work will be the interest of the authors' future work.

\section{Data Availability}

The data used to support the findings of this study are available from the corresponding author upon request.

\section{Conflicts of Interest}

The authors declare that they have no conflicts of interest.

\section{Acknowledgments}

The authors gratefully acknowledge the research grants provided by the National Natural Science Foundation of
China (nos. 51768044, 51908268, and 51968047) and Jiangxi Postdoctoral Science Foundation (2019KY57).

\section{References}

[1] GB50010-2010, Code for Seismic Design of Buildings, Architecture \& Building Press, Beijing, China, 2016.

[2] GB18306-2015, Seismic Ground Motion Parameters Zonation Map of China, China Architecture \& Building Press, Beijing, China, 2015.

[3] X. L. Lu, D. Y. Wu, and Y. Zhou, "State-of-the-art of earthquake resilient structures," Journal of Building Engineering, vol. 40, no. 2, pp. 1-15, 2019.

[4] Q. G. Xu, Design of Precast Concrete structure, China Architecture \& Building Press, Beijing, China, 2017.

[5] J. W. Ma, J. L. Pan, W. Y. Yin et al., "Experimental study on seismic behavior of wholly precast RC frame-shear wall structure," Journal of Building Engineering, vol. 38, no. 6, pp. 12-22, 2017.

[6] S. J. Hu, Y. C. Xiong, and Z. Wang, "Research status review on eccentrically braced frames," Progress in Steel Building Structures, vol. 21, no. 2, pp. 1-14, 2019.

[7] S. Kazemzadeh Azad and C. Topkaya, "A review of research on steel eccentrically braced frames," Journal of Constructional Steel Research, vol. 128, pp. 53-73, 2017.

[8] F. Wang, M. Su, M. Hong, Y. Guo, and S. Li, "Cyclic behaviour of Y-shaped eccentrically braced frames fabricated with highstrength steel composite," Journal of Constructional Steel Research, vol. 120, pp. 176-187, 2016.

[9] X. D. Ji, Q. F. Ma, Y. D. Wang et al., "Cyclic tests of replaceable shear links in steel coupling beams," Journal of Building Structures, vol. 35, no. 6, pp. 1-10, 2014.

[10] S. J. Hu, J. G. Xiong, and Z. Wang, "Study of mechanical properties and its influence factors for short shear links," Engineering Mechanics, vol. 35, no. 8, pp. 144-153, 2018.

[11] T. Okazaki and M. D. Engelhardt, "Cyclic loading behavior of EBF links constructed of ASTM A992 steel," Journal of Constructional Steel Research, vol. 63, no. 6, pp. 751-765, 2007.

[12] A. Ghobarah and H. Abou Elfath, "Rehabilitation of a reinforced concrete frame using eccentric steel bracing," Engineering Structures, vol. 23, no. 7, pp. 745-755, 2001.

[13] G. Wu and D. C. Feng, "Research progress on fundamental performance of precast concrete frame beam-to-column connections," Journal of Building Engineering, vol. 39, no. 2, pp. 1-16, 2018.

[14] S. J. Hu, X. F. Wang, J. G. Xiong, and S. Z. Zeng, "Seismic performance analysis of Y-shaped eccentrically braced frames with SSL-SSBC," Journal of Vibration and Shock, vol. 39, no. 22, pp. 85-93, 2020.

[15] F. M. Mazzolani, G. D. Corte, and M. D’Aniello, “Experimental analysis of steel dissipative bracing systems for seismic upgrading," Journal of Civil Engineering and Management, vol. 15, no. 1, pp. 7-19, 2009.

[16] C. Durucan and M. Dicleli, "Analytical study on seismic retrofitting of reinforced concrete buildings using steel braces with shear link," Engineering Structures, vol. 32, no. 10, pp. 2995-3010, 2010.

[17] B. C. Zhao, A. L. Yu, J. L. Wang et al., "Experimental investigation of hysteretic behavior of RC frames filled with Y-steel brace," Journal of Building Engineering, vol. 34, no. 8, pp. 107-118, 2013.

[18] G. H. Sun, Y. Shao, A. L. Yu et al., "Hysteretic behavior of connection joints between RC frame beam with floor and and 
energy dissipation link," Engineering Mechanics, vol. 32, no. 7, pp. $47-56,2015$.

[19] AISC 341-16, Seismic Provisions for Structural Steel Buildings, American Institute of Steel Construction (AISC), Chicago, IL, USA, 2016.

[20] C. Xu, K. Sugiura, C. Wu, and Q. Su, "Parametrical static analysis on group studs with typical push-out tests," Journal of Constructional Steel Research, vol. 72, pp. 84-96, 2012.

[21] H. Chen, Z. X. Guo, Y. Liu et al., "Study on the shear resisting mechanism and strength for an innovative composite shear connector," Engineering Mechanics, vol. 36, no. 3, pp. 159$168,2019$.

[22] C. C. Chul, J. W. Lee, and J. S Kim, "Shear strength of T-type Perfobond rib shear connectors," KSCE Journal of Civil Engineering, vol. 20, no. 5, pp. 1824-1834, 2016.

[23] Q. Han, J. Y. Wang, and Y. XingYang, "Numerical analysis on shear stud in push-out test with crumb rubber concrete," Journal of Constructional Steel Research, vol. 130, pp. 148-158, 2017.

[24] S.-H. Kim, K.-S. Kim, S. Park, C.-Y. Jung, and J.-G. Choi, "Comparison of hysteretic performance of stubby Y-type perfobond rib and stud shear connectors," Engineering Structures, vol. 147, pp. 114-124, 2017.

[25] E. Baran and C. Topkaya, "An experimental study on channel type shear connectors," Journal of Constructional Steel Research, vol. 74, pp. 108-117, 2012.

[26] GB50010-2010, Code for Design of Concrete Structures, China Architecture \& Building Press, Beijing, China, 2015.

[27] GB50017-2017, Standard for Design of Steel Structures, China Architecture \& Building Press, Beijing, China, 2017.

[28] S. Hu, J. Xiong, Q. Zhou, and Z. Lin, "Analytical and numerical investigation of overstrength factors for very short shear links in EBFs," KSCE Journal of Civil Engineering, vol. 22, no. 11, pp. 4473-4482, 2018. 